\title{
Extinction Ratio and the Fiber Optic Transmission Networks
}

\author{
Ved Nath Jha*, Supriya Rani and Ved Nath Jha Faculty ${ }^{1}$ \\ Physical Sciences, Mangalayatan University Extended \\ NCR 33rd, Milestone, Aligarh, Mathura, Highway, Beswan, Uttar Pradesh, India \\ ${ }^{2}$ Supriya Rani Faculty of Physics, Magadh Mahila College, Patna University, Patna, Bihar, India. E- \\ mail: supriya.physics@ gmail.com \\ *Correspondence concerning this article should be addressed to Ved Nath Jha, E-mail: \\ ved.jha@mangalayatan.edu.in
}

Article History: Received: 10 November 2020; Revised 12 January 2021 Accepted: 27 January 2021; Published online: 5 April 2021

\begin{abstract}
In the fiber optic communication network for example,- FTTH, EPON, NBN, OTN and so on, the most important components are fiber length between transmitter and receiver point. So, to make, cheap and meaningful communication through optical fiber it must be required to calculate how and what amount of signal is transmitted with the given length of the fiber. Finally, it is said that the optical fiber network have several limitations like extension ratio. So, it is necessary to investigate its affect on the performance of the Optical Network. This research is based on simulation by OptiSystem 0.17 on the basis of Dense wavelength division multiplex (DWDM) technology, Erbium Doped Fiber Amplifier (EDFA), dispersion Compensating Fiber (DCF) and single mode fiber of length $50-100 \mathrm{~km}$
\end{abstract}

Keywords: extinction ratio, linear impairment, nonlinear impairment, DWDM, EDFA, dispersion, XPM

At the first instance Charles K. Kao and Hockman in 1966 thought about the unacceptable loss of signal strength approximately $1,000 \mathrm{~dB} / \mathrm{km}$ in the fiber due to its impurities and that could be eliminated (Kapron, Keck, \& Maurer, 1970). Since the fiber has been used in worldwide optical communication with the revolutionized technology and the laser source that provides the coherent signal (Vidmar, 2001; Agrawal, 1997). Again on the basis of parameters like bit rate $(B)$ and spacing between repeaters of the optical fiber networks $(L)$, then fiber optic communication is divided into the five generations (Vidmar, 2001; Agrawal, 1997; Addanki, Amiri, \& Yupapin, 2018; Mizkuš, 2010; Bansal, Singh, \& Gupta, 2008). Conventionally, the information signal is used to modulate the intensity of carrier signal, and then the signal of information propagates through the fiber and finally detected by the detector (Photodiode) at the receiver point. Since the intensity modulation of the carrier wave at the transmitter end and the direct detection of it at the detector end, both are collectively called intensity modulation and direct detection scheme (IMDD). At the time of detection of transmitted signal by the photodiode the information is lost due to the change in phase of that signal as per the power law. This loss in the information signal prevents the use of the phase modulation scheme like PSK, MPSK and QAM. Therefore, the spectral and power efficiency are limited in fiber optic communication system using direct detection scheme. Again, by the invention of an Erbium Doped Fiber Amplifier (EDFA) (Al-ithawi, characterization of optical fibers containing nanoparticles doped rare earth as an amplifier for telecommunications, 2018; Maiman, 1960), loss of 
optical fiber networks of long distance minimized in the $C$-band and $L$-band (Addanki, Amiri, \& Yupapin, 2018; Gorshe, 2009). Also, EDFA can simultaneously amplify the optical signal. So, it is used with WDM technology.

Furthermore, by the advent of InGaAsP semiconductor laser and optical backward propagation detection technique (Mateo, Zhu, \& Li, 2008; SERIES G: TRANSMISSION SYSTEMS AND MEDIA, DIGITAL SYSTEMS AND NETWORKS - Transmission media and optical systems characteristics -Optical fibre cables, (2016); Liptai, Dolník, Pavlík, Zbojovský, \& Špes, 2017), the fiber channel operated near 1,300-nm wavelength and fiber loss became $1 \mathrm{~dB} / \mathrm{km}$. After, the 20 years continuous effort of scientist, in the optical fiber communication, it is observed that BL product increased generation to generation and in the decades of 2000s we entered in the fourth generation communication system with the bit rate $160 \mathrm{Gbs}$ and repeater's spacing $35,000 \mathrm{~km}$ and operating wavelength range 1.53-1.5 $\mu \mathrm{m}$ (Liu, 2019). Optical Fiber in fifth Generation -While WDM system greatly improved the transmission capacities of the fiber with the simultaneously operating higher wavelength range by the use of Raman amplification techniques. Thus we can say that in this generation the signal spectral efficiency is improved (Bosternák \& Róka, 2018; Smiesko \& Uramova, 2012). And to remove the drawbacks of the direct detection, the coherent fiber optic system is introduced to do the coherent detection or phase detection of an optical signal of transmitter. It means coherent detector can detect any information carried by the phase and frequency of the transmitted signal. Also, the development of digital signal processing for high speed allows us the implementation of phase locking, frequency synchronization and control over polarization in electronic domain that is with the help of coherent detection system and digital signal processing both amplitude and phase information detected (Badraoui, Berceli, \& Singh, 2017). Furthermore, due to the coherent detection all the optical parameters like amplitude, phase, frequency and polarization are available in the electrical domain so, it is helpful to design the advanced modulator. It is also proved that the optical modulator with semiconductor laser increases not only the operational performance but the stability in the optical signal throughout the communication, with the application of compensation technique of nonlinearity, the optical spectrum becomes $10 \mathrm{THz}$ and per channel capacity approaches to $64 \mathrm{Tbps}$ by 2022 (Addanki, Amiri, \& Yupapin, 2018; Liu, 2019).

To improve the power efficiency of the optical fiber communication system, minimize the major drawbacks of the fiber channel like linear and nonlinear impairments (Gordon \& Mollenauer, 1990; Batagelj, Janyani, \& Tomažič, 2014). Actually, in the fiber optic transmission system, signal power can be improved by highly sensitive optical receiver for a noise limited transmission that is power loss can be compensated by amplifier. But the ultimate demand of this information era, higher bandwidth with highest possible data speed is compensated only and only by improving the power efficiency and spectral efficiency of the system (Addanki, Amiri, \& Yupapin, 2018). Linearity of fiber: Due to the linear impairment (Ryu, 1991) of the optic fiber, the fiber behaves as the linear medium at the smaller optical power of transmission. To remove this impairment, Generally, we consider one by one of their types, as (1) Attenuation - it decreases the strength of signal in the fiber due to scattering, absorption and physical bending. Experimentally, it is observed that the attenuation can be compensated by the amplifier. (2) Chromatic dispersion - if the propagation speeds of different wavelengths are different and intersymbol interference takes place, then it indicates that the existence of chromatic dispersion due to the pulse spreading. Since the greater bit rate propagation for the long distance becomes possible by the use of DCF (dispersion Compensating Fiber) like $\mathrm{LiNbO}_{3}$ fiber. (3) Polarization mode dispersion - It is really most dominant linear effect for limiting the channel capacity by pulse broadening of the output signal of the system. It can be reduced by deterministic 
differential group delay method and birefringence of the fiber. (4) Cross-talk - it is most common in the dense WDM system due to the decreasing channel spacing and increasing data. It can be reduced by the use of $R$-Z format or by filter cascading or double polarization method. Nonlinearity of Fiber: -It is observed that due to higher power or bit rate of transmission, the optical fiber behaves as nonlinear medium (Ryu, 1991; Chraplyvy, 1990; Lyubomirsky et al., 2003) and concerned defects influence the performance of the technology of fiber optic transmission. To reduce the effect of them, they are considered as (1). Scattering Based: -when optic signal propagates at high bit rate then having scattering of signal through fiber that affects the energy of the signal pulse. Like SBS, SRS and so on (2) Refractive Index Based: -Like SPM, XPM that leads to the deformation of signal pulse due to the change in refractive index of the fiber with the wavelength of the signal (Ryu, 1992). Using WDM technique, through the same optical fiber multiple signals can be transmitted, and if during propagation the intensity of one optic signal fluctuates and modulates the phase of any other optic signal, it leads to the cross-phase modulation phenomena (XPM) (Srivastava \& Kapoor; Fusaro et al., 2019; Kikuchi \& Sasaki, 1995). That is Kerr nonlinearity of the index of refraction must be depend upon the susceptibility of the applied electric field inside the fiber channel. As XPM (Rongqing Hui, Demarest, \& Allen, 1999; Karfaa, Ismail, Abbou, Shaari, \& Majumder, 2008; Huszaník, Turán, \& Ovseník, 2018) gives more limitations than SPM for the given optical fiber transmission with the WDM techniques.

As the second order susceptibility does not exist in the silica glass due to symmetricity of its molecules, so the all-nonlinear effects like nonlinear polarization in the optical fiber can be determined by third order susceptibility. When signal power in the optical fiber fluctuates due to the addition of noise of the amplifier leads the phase fluctuation, which degrades the performance by the devaluation of OSN ratio. After all it is said that the fiber nonlinearities exist as the signal becomes strong so it dominantly limits the upper boundary of the signal power. Finally, it is investigated the elimination of XPM with the optical fiber dispersion by the variation of transmitting power level. Treatment of Nonlinearity (XPM) by the adjustment of Power Level in Optical Fiber Communication with Dense wavelength division multiplex (DWDM) system (Nain, Jadon, \& Mishra; Ivaniga \& Ivaniga, 2019; Ivaniga \& Ivaniga, 2019; Kovac, Lukacs, \& Gladisova; Ivaniga, Ivaniga, Turan, \& Ovsenik, 2017; Archana \& Krithika, 2015; Ruzbarsky, Turan, \& Ovsenik; Bachrata \& Bachraty, 2012) to attain the data transmission rate that increases approximately 1.5 times per year. Most recently the DWDM system (Ivaniga \& Ivaniga, 2019b; Agrawal, 2008) is developed which can have the transmission capacity 100 Gbps per unit length. Now the basic fact of this system that is, each wavelength has its own virtual fiber as shown in the Figure 1.

As the performance of optical fiber network evaluated in terms of quality factor and bit error rate then the role extinction ratio cannot be neglected because the slight change in extinction ratio indirectly affects the constancy and the minimal value of BER. 


\section{Simulation}

Now with the basic components like EDFA, DCF (Dispersion Fiber) the DWDM technology based optical network with single mode fiber $(50-100 \mathrm{~km})$ prepared for simulation as given in the Figure 1.

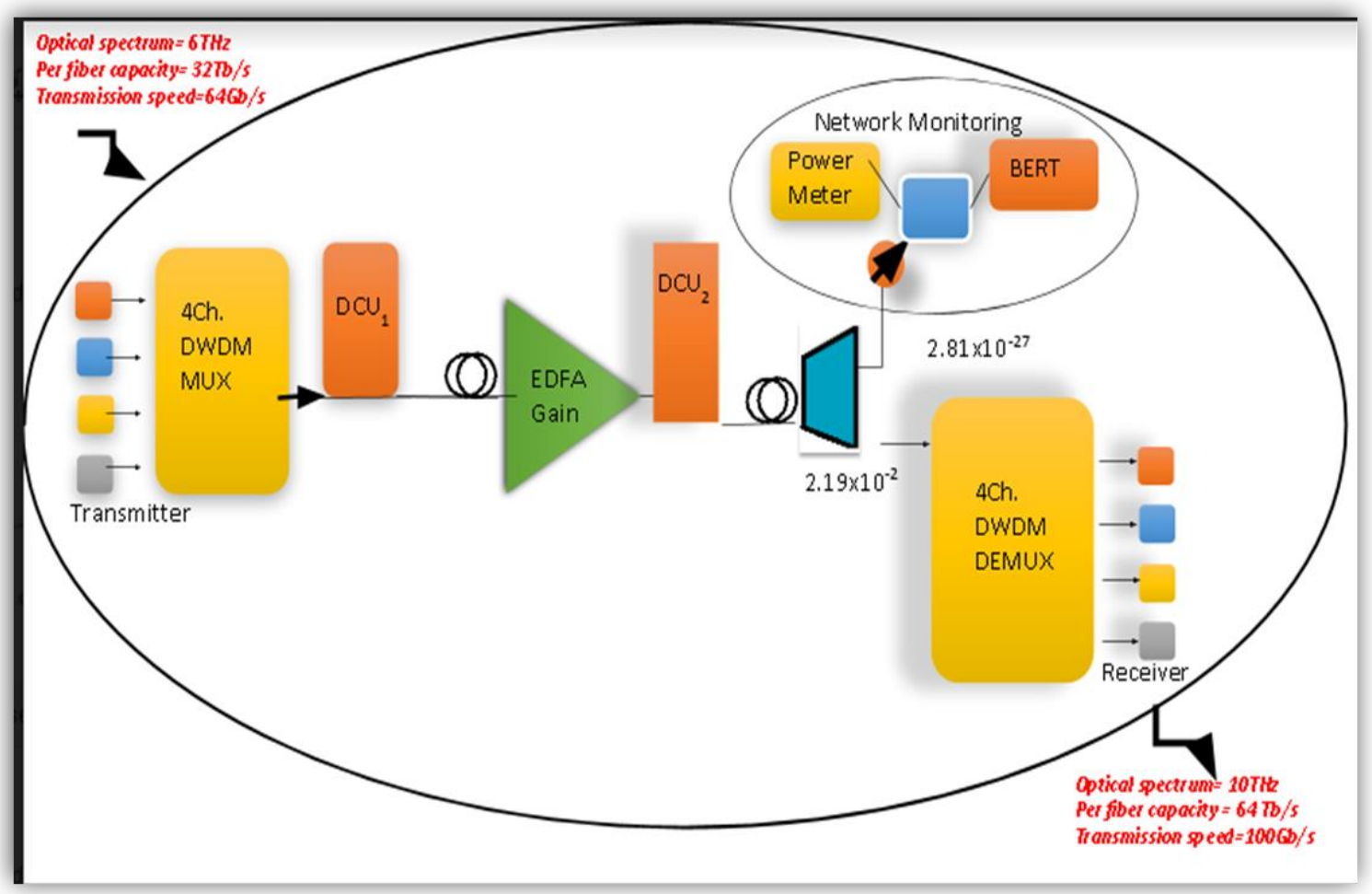

Figure 1. Design of four channel DWDM Network with different extinction ratio

On the basis of OptiSystem programing software this four-channel DWDM system with EDFA amplifier and dispersion compensator is designed to eliminate the nonlinearity due to XPM by changing the input Optical Power density in the adjacent channels. In which EDFA output power is set at $10 \mathrm{~dB}$ and Optical Fiber behind the amplifier is of length $50-100 \mathrm{~km}$.

Table 1

Simulation Parameters of the fiber network shown in the Figure 1

\begin{tabular}{ll}
\hline Parameter & Values \\
\hline Transmitter frequency & $1555(\mathrm{~nm})$ \\
\hline Power of each channel & $-10(\mathrm{dBm})$ \\
\hline Frequency spacing & $100(\mathrm{GHz})$ \\
\hline Modulation format & NRZ \\
\hline Fiber length & $50(\mathrm{~km})$ and $100(\mathrm{~km})$ \\
\hline Number of loops & 5 \\
\hline EDFA gain & $10(\mathrm{~d} B)$ and $14 \mathrm{~m}$ length \\
\hline Cut off frequency & \\
& $0.75 *$ Bit rate \\
\hline
\end{tabular}

Abbreviations: EDFA

Erbium Doped Fiber Amplifier. 


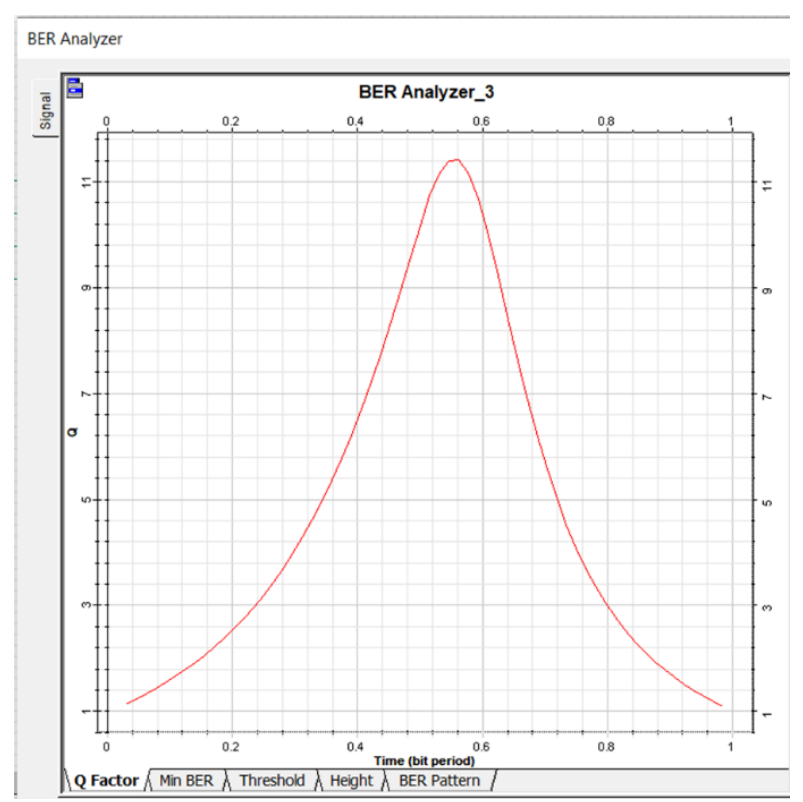

Figure 2. Variation of quality factor with time in NRZ format for $50 \mathbf{~ k m}$

\section{Graphical Analysis of Simulation}

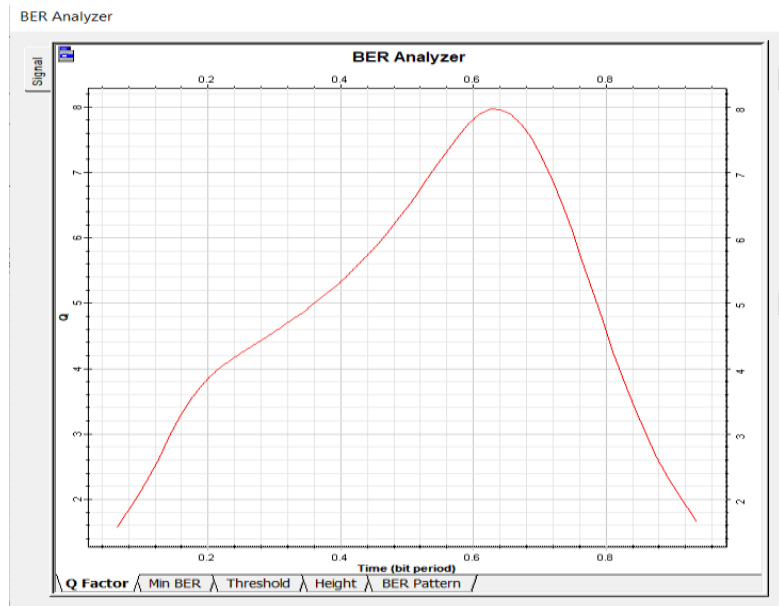

Figure 3. Variation of quality factor with time in NRZ format for $100 \mathbf{~ k m}$

Table 2

At High Extinction Ratio, calculation of Quality Factor and BER from the Figure-2 and 3.

\begin{tabular}{lllll}
\hline S. No & SMF length $(\mathrm{km})$ & $\begin{array}{l}\text { Signal } \\
\text { power( }(\mathrm{dBm})\end{array}$ & $\begin{array}{l}\text { Maximum } \\
\text { Quality factor }\end{array}$ & Minimum BER \\
\hline 1. & 50 & -10 & 11.04190 & $1.86939 \mathrm{e}-030$ \\
\hline 2. & 100 & -10 & 7.09624 & $6.43275 \mathrm{e}-016$ \\
\hline
\end{tabular}

Eye Diagram Analysis: -On the basis of Figure 4, It is observed that by increasing the extinction ratio and asymmetrical distribution of in input powers in this DWDM network, bit error rate becomes smaller with higher quality factor which is shown by the maximal eye opening in Figure 4. Whereas 
the distortion in the upper part of the eye pattern shows that high extinction ratio gives negative effect directly and indirectly on the components of the Networks.

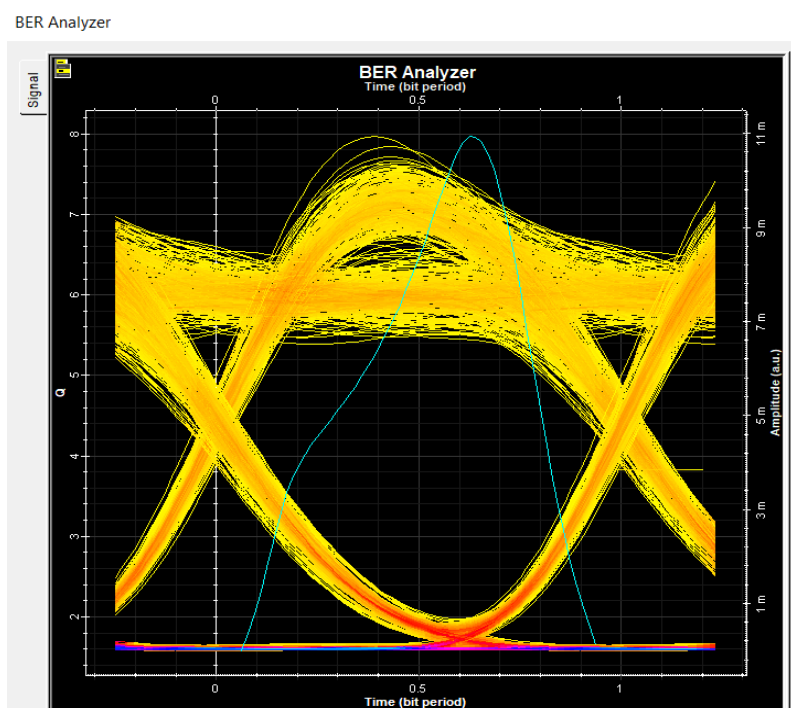

Figure 4. Eye Diagram of eye Height $\mathbf{0 . 0 0 4 9 8 7 9 5}$ for high extinction ratio (ER)

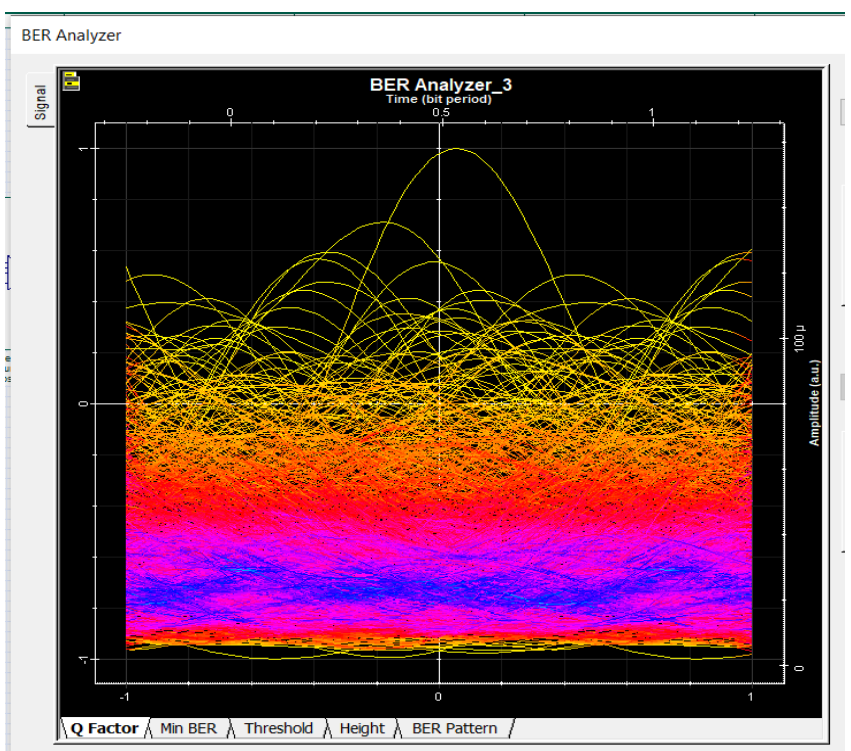

Figure 5. Eye Diagram of closed eye or eye Height 0.0 for high extinction ratio (ER)

Table 3

Calculation of $Q$-factor and BER at particular value of fiber length and High Extinction Ratio

\begin{tabular}{llllll}
\hline S. No & $\begin{array}{l}\text { Total SMF } \\
\text { length }(\mathrm{km})\end{array}$ & Extinction ratio & DCF length $(\mathrm{km})$ & $\begin{array}{l}\text { Max.Quality } \\
\text { factor }\end{array}$ & Minimum BER \\
\hline 1. & 50 & $30 \mathrm{~dB}$ & 10 & 11.40190 & $1.86939 \mathrm{e}-030$ \\
& & & & & \\
\hline 2. & $30 \mathrm{~dB}$ & 10 & & $6.43275 \mathrm{e}-016$
\end{tabular}


Furthermore to improve the quality factor of the signal, emphasized on the asymmetrical distribution of input powers of producing fixed dispersion values in the fiber,the power spectrum shows better result.

In this simulation, all the parameters are kept constant with Low Extinction Ratio

Table 4

Calculation of $Q$-factor and BER at particular value of fiber length and Low Extinction Ratio

\begin{tabular}{llllll}
\hline S. No & $\begin{array}{l}\text { Total SMF } \\
\text { length }(\mathrm{km})\end{array}$ & Extinction ratio & DCF length $(\mathrm{km})$ & $\begin{array}{l}\text { Max.Quality } \\
\text { factor }\end{array}$ & Minimum BER \\
\hline 1. & 50 & $7 \mathrm{~dB}$ & 10 & 7.852 & $1.98928 \mathrm{e}-015$
\end{tabular}

\begin{tabular}{llllll}
\hline 2. & 100 & $7 \mathrm{~dB}$ & 10 & 3.790 & $3.843 \mathrm{e}-005$
\end{tabular}

Abbreviations: DCF dispersion Compensating Fiber.

Now on the basis of graphical analysis of Figures 2, 3 and 4 and the tabular data of Tables 1, 2 and 4, it can be obtained that there must be the relation between Extinction Ratio and quality factor of the Network.

Also, it is crystal clear information that the highest possible quality factor attended at higher power of Extinction Ratio and vice-versa. At last, but not least, the small change in Extinction Ratio shows larger difference in the value of power required to make stable and lower bit error rate.

\section{Conclusion:}

The main aim of this research is to describe the effect of extinction ratio on the Optical Fiber network for the particular fiber length and this simulation proved that in the Optical Fiber, the highest quality factor attended for the higher value of extinction ratio as per the Tables $3 \& 4$. Also, each of the fiber optic network must have the specific range of ER that gives the better performance.

Furthermore, it is required that to investigate and differentiate the direct and indirect effect of ER on the transmission of signal through the fiber network.

\section{Acknowledgments:}

We would like to thankful to Mangalayatan University, Aligarh for granting leave to carry out the research work and a special thank for Yogendra Kumar Prajapati, Dept. of ECE, MNNIT, Allahabad for his unconditional support to complete this work in his Lab. Also, we would like to acknowledge Sawyer Jie, Optiwave for his kind cooperation.

\section{References}

[1]. Addanki, S., Amiri, I. S., \& Yupapin, P. (2018). Review of optical fibers-introduction and applications in fiber lasers. Results in Physics, 10, 743-750. doi:10.1016/j.rinp.2018.07.028

[2]. Agrawal, G. P. (1997). Fiber-optic communication systems (2nd ed). New York: Wiley.

[3]. Agrawal, G. P. (2008). Applications of nonlinear fiber optics. Retrieved from http://www.sciencedirect.com/science/book/9780123743022. Amsterdam, Boston: Elsevier.

[4]. Archana, B., \& Krithika, S. (2015). Implementation of BB84 quantum key distribution using OptSim. In 2nd international conference Electronic Communal Syst. ICECS, IEEE, Coimbatore, India, 2015 (pp. 457-460). doi:10.1109/ECS.2015.7124946 
[5]. Bachrata, K., \& Bachraty, H. (2012). Computer as a tool for changing attitudes towards mathematics. Proceedings of the 2012 IEEE 10th International Conference Emergencies Elearning Technol. Appl. ICETA. Star Lesn Slovakia (pp. 21-25).

[6]. Badraoui, N., Berceli, T., \& Singh, S. (2017). Distortion cancellation for solitons carrying high-speed information in WDM systems. In I. Netw, IEEE, Girona \& Spain (Eds.) 19th international conference Transparent Opt, 2017 (pp. 1-4). doi:10.1109/ICTON.2017.8024967

[7]. Bansal, S., Singh, S., \& Gupta, S. (2008). Performance analysis of a gain clamped 16, 40 Gb/S WDM optical communication system, in: 2008 Int. Communications and Network. conference Signal Process (pp. 396-400). doi:10.1109/ICSCN.2008.4447226. Chennai, India: IEEE Publications.

[8]. Batagelj, B., Janyani, V., \& Tomažič, S. (2014). Research challenges in optical communications towards 2020 and beyond. J. Microelectron. Electron. Compon. Mater., 44, 177-184.

[9]. Bosternák, Z., \& Róka, R. (2018). Bandwidth scheduling methods for the upstream traffic in passive optical networks. Przeglad Elektrotechniczny, 94, 9-12.

[10]. Chraplyvy, A. R. (1990). Limitations on Lightwave communications imposed by optical-fiber nonlinearities. Journal of Lightwave Technology, 8(10), 1548-1557. doi:10.1109/50.59195

[11]. Fusaro, A., Berti, N., Guasoni, M., Jauslin, H. R., Picozzi, A., Fatome, J., \& Sugny, D. (2019). Self-polarization effect in the middle point of an optical fiber. Physical Review. Part A, 99(4). doi:10.1103/PhysRevA.99.043826, PubMed: 043826

[12]. Gordon, J. P., \& Mollenauer, L. F. (1990). Phase noise in photonic communications systems using linear amplifiers. Optics Letters, 15(23), 1351-1353. doi:10.1364/OL.15.001351

[13]. Gorshe, S. (2009). A tutorial on ITU-T G, 709 optical transport networks.

[14]. Huszaník, T., Turán, J., \& Ovseník, L. (2018). Impact of the optical fiber nonlinear phenomenon on the 16-channel DWDM OC-768 long-haul link. Elektrotechniski Vestn., 85, $255-262$.

[15]. S. (2018). Al-ithawi, characterization of optical fibers containing nanoparticles doped rare earth as an amplifier for telecommunications. International Journal of Nanoelectronics and Materials, 11, 49-60.

[16]. Ivaniga, P., \& Ivaniga, T. (2019). The design of EDFA with forward pumping at the distance line in DWDM. Journal of Engineering Science and Technology, 14, 531-540.

[17]. Ivaniga, T., \& Ivaniga, P. (2019). Suppression of nonlinear XPM phenomenon by selection of appropriate transmit power levels in the DWDM system. International Journal of Optics, 2019, 1-8. doi: $\underline{10.1155 / 2019 / 9357949}$

[18]. Ivaniga, T., Ivaniga, P., Turan, J., \& Ovsenik, L. (2017). Retrieved from http://communications.uniza.sk/index.php/communications/article/view/240. Analysis of possibilities of increasing the spanned distance using EDFA and DRA in DWDM system, Commun. Sci [Lett]. University Zilina, 19.

[19]. Kapron, F. P., Keck, D. B., \& Maurer, R. D. (1970). Radiation losses in glass optical waveguides. Applied Physics Letters, 17(10), 423-425. doi:10.1063/1.1653255

[20]. Karfaa, Y. M., Ismail, M., Abbou, F. M., Shaari, S., \& Majumder, S. P. (2008). Channel spacing effects on XPM crosstalk in WDM networks for various fiber types, in: 2008 6th national conference Telecommunication Technologia 2nd Malaysia conference Photonics, IEEE, Putrajaya, Malaysia, 2008 (pp. 1-5). doi:10.1109/NCTT.2008.4814224

[21]. Kikuchi, N., \& Sasaki, S. (1995). Analytical evaluation technique of self-phase-modulation effect on the performance of cascaded optical amplifier systems. Journal of Lightwave Technology, 13(5), 868-878. doi:10.1109/50.387804 
[22]. Kovac, O., Lukacs, P., \& Gladisova, I. Textures classification based on DWT, in: 2018 28th international conference Radìoelektronika Radìoelektronika, IEEE, Prague, 2018 (pp. 1-5). doi:10.1109/RADIOELEK.2018.8376379

[23]. Liptai, P., Dolník, B., Pavlík, M., Zbojovský, J., \& Špes, M. (2017). Check measurements of magnetic flux density: Equipment design and the determination of the confidence interval for EFA 300 measuring devices. Measurement, 111, 51-59. doi:10.1016/j.measurement.2017.07.022

[24]. Liu, X. (2019). Evolution of fiberoptic transmission and networking toward the 5G eraIScience. iScience, 22, 489-506. doi:10.1016/j.isci.2019.11.026

[25]. Lyubomirsky, I., Tiequn Qui, T., Roman, J., Nayfeh, M., Frankel, M. Y., \& Taylor, M. G. (2003). Interplay of fiber nonlinearity and optical filtering in ultradense WDM. IEEE Photonics Technology Letters, 15(1), 147-149. doi:10.1109/LPT.2002.805864

[26]. Maiman, T. H. (1960). Stimulated optical radiation in Ruby. Nature, 187(4736), 493-494. doi: $10.1038 / 187493 \mathrm{a} 0$

[27]. Mateo, E., Zhu, L., \& Li, G. (2008). Impact of XPM and FWM on the digital implementation of impairment compensation for WDM transmission using backward propagation. Optics Express, 16(20), 16124-16137. doi:10.1364/OE.16.016124

[28]. Mizkuš, L. (2010). Evaluations of the error rate in backbone networks. Elektrorevue, 12, 110.

[29]. Nain, H., Jadon, U., \& Mishra, V. Evaluation and analysis of non-linear effect in WDM optical network, in: 2016 IEEE Int. conference Recent Trends Electronic Inférieure Communal Technologia RTEICT, IEEE, Bangalore, India, 2016 (pp. 36-39). doi:10.1109/RTEICT.2016.7807777

[30]. Rongqing Hui, R., Demarest, K. R., \& Allen, C. T. (1999). Cross-phase modulation in multispan WDM optical fiber systems. Journal of Lightwave Technology, 17(6), 1018-1026. doi:10.1109/50.769302

[31]. Ruzbarsky, J., Turan, J., \& Ovsenik, L. Stimulated Brillouin scattering in DWDM all optical communication systems, in: 2016 26th international conference Radìoelektronika Radìoelektronika, IEEE, Kosice, Slovakia, 2016 (pp. 395-398). doi:10.1109/RADIOELEK.2016.7477354

[32]. Ryu, S. (1991). Signal linewidth broadening due to fibre nonlinearities in long-haul coherent optical fibre communication systems. Electronics Letters, 27(17), 1527. doi: $10.1049 / \mathrm{el}: 19910960$

[33]. Ryu, S. (1992). Signal linewidth broadening due to nonlinear Kerr effect in long-haul coherent systems using cascaded optical amplifiers. Journal of Lightwave Technology, 10(10), 1450-1457. doi:10.1109/50.166789

[34]. SERIES G: TRANSMISSION SYSTEMS AND MEDIA, DIGITAL SYSTEMS AND NETWORKS-Transmission media and optical systems characteristics -Optical fibre cables, (2016).

[35]. Smiesko, J., \& Uramova, J. (2012). Access node dimensioning for IPTV traffic using effective bandwidth. Komunikacie, 14, 11-16.

[36]. Srivastava, M., \& Kapoor, V. Analysis and compensation of self phase modulation in wavelength division multiplexing system, in: 2014 Stud. conference Engenharia System, IEEE, Allahabad, India, 2014 (pp. 1-4). doi:10.1109/SCES.2014.6880074

[37]. Vidmar, M. (2001). Optical-fiber communications: Components and systems. Informacije MIDEM, 31, 246-251. 